\title{
A Successful Pregnancy Outcome after Surgical Decompression of Type I Arnold-Chiari Malformation
}

\author{
Patricia Ip*, Susmita Pankaja, Fidelma 0’Mahony \\ Department of Obstetrics \& Gynaecology, University Hospital of North Staffordshire NHS Trust, \\ Stoke-on-Trent, UK \\ Email: ${ }^{*}$ triciaaa29@hotmail.com
}

Received 20 November 2014; accepted 2 December 2014; published 15 January 2015

Academic Editor: Chris Constantinou, Stanford University Medical School, USA

Copyright (C) 2015 by authors and Scientific Research Publishing Inc.

This work is licensed under the Creative Commons Attribution International License (CC BY).

http://creativecommons.org/licenses/by/4.0/

(c) (i) Open Access

\section{Abstract}

Type I Arnold-Chiari malformation (ACM) usually presents in adulthood and consists of a downward displacement of the cerebellar tonsils through the foramen magnum. A 25-year-old woman presented with a 5-month history of headache associated with blurred vision, tinnitus and sickness. Imaging recognised the need for surgical intervention, but whilst awaiting for surgery she fell pregnant. Considering the risks of neurological deterioration, the woman underwent surgical decompression of type I ACM at 15 weeks gestation. She subsequently presented with progressively worsening headaches during late pregnancy from 35 weeks. The obstetric plan was initially induction of labour at term but since the onset of worsening symptoms, this date was brought forward to $39+1$ weeks gestation. She proceeded to have a normal delivery with no neonatal complications and an uneventful puerperium followed. Since the delivery, the patient reported fewer symptoms, showed no signs of neurological deficit and a repeat magnetic resonance imaging of the head showed good relief of neural compression. This case illustrates how judicious selection of the appropriate mode of delivery of women following surgically corrected ACM and a multidisciplinary approach is critical in the successful management of the antepartum period and labour.

\section{Keywords}

Arnold-Chiari Malformation, Pregnancy, Anaesthetics

\footnotetext{
${ }^{*}$ Corresponding author.
}

How to cite this paper: Ip, P., Pankaja, S. and O'Mahony, F. (2015) A Successful Pregnancy Outcome after Surgical Decompression of Type I Arnold-Chiari Malformation. Open Journal of Obstetrics and Gynecology, 5, 44-48. 


\section{Introduction}

Arnold-Chiari malformation (ACM), types I to IV, refer to a group of congenital hindbrain anomalies affecting the cerebellum, medulla, upper cervical part of the spinal cord and the base of the skull [1]. These disorders can lead to altered craniospinal pressure and abnormal flow of cerebrospinal fluid.

ACM type I malformation is the most common but the least severe form of the spectrum [2]. Based on studies, the incidence of ACM type I remains unclear [3]. However, retrospective investigation of magnetic resonance imaging (MRI) of the head revealed that the prevalence may be as high as 1 in 1280 [4]. ACM type I is characterised by the prolapse of the cerebellar tonsils below the foramen magnum [5]. Patients with ACM type I are generally asymptomatic during childhood. It presents typically in adulthood with headache, pain in the neck and upper extremities and other neurological signs which are suggestive of raised intracranial pressure [1] [2] [6]. Type I ACM may also lead to the development of syringomyelia or spinal cord cavitation, which can lead to additional neurological problems [7].

ACM type II is less common but more severe when compared to ACM type I and is almost invariably associated with myelomenigocoele [1] [2]. Dysfunction of brainstem and lower cranial nerve are the most serious features of this form [8]. ACM type III refers to herniation of cerebellum into a high cervical myelomeningocoele and type IV is cerebellar agenesis [9]. Types III and IV are exceedingly rare and generally incompatible with life. Therefore they are of scant clinical significance.

Special concern for young pregnant women affected by ACM type I is the safety of pregnancy and delivery owing to the significant potential maternal morbidity and mortality [10]. There are very few articles addressing pregnant women with ACM and the best management during delivery remains controversial. Careful selection of mode of delivery and use of anaesthetic of women following surgically corrected ACM is of paramount importance as this rare disorder is associated with the potential risk of brainstem herniation and spinal column compression during labour [9].

We described a successful pregnancy outcome in a patient whose progressive symptoms were halted by surgical decompression of ACM in the second trimester of pregnancy.

\section{Case}

A 25-year-old gravida 4 para 3 woman, at 11 weeks gestational age, was referred to the Obstetric Team following the diagnosis of type 1 ACM. She first presented to the Neurology Team with a 5-month history of headache associated with blurred vision, tinnitus and sickness occurring at weekly intervals. She was otherwise fit and well.

Computed tomography (CT) and MRI of the head and spine were arranged and the results showed ACM type I with downward herniation of cerebellar tonsil of about $17 \mathrm{~mm}$ below the foramen magnum and mild thoracic syrinx (Figure 1). The patient was referred to the Neurosurgical Team for consideration of surgical correction. Nevertheless, she found herself pregnant prior to the scheduled operation. As the patient would have reached her second trimester on the day of surgery, the multidisciplinary team agreed that the benefit of surgery outweighed operative and anaesthetic risks to the fetus. At 15 weeks gestation, she underwent foramen magnum decompression and C1 laminectomy.

There was significant improvement of her symptoms post-operatively. The patient had an uneventful second trimester. Fetal growth scans were all normal at 28 and 33 weeks gestation. The birth plan for the patient was to proceed with normal delivery at term since she had 3 previous uncomplicated normal vaginal deliveries with no other contra-indication identified in antenatal check-ups.

The patient started experiencing persistent headache at 35 weeks. There was no papilloedema or sign of raised intracranial pressure (ICP) noted on clinical examination. There was minimal benefit with analgesia. After discussion with the Neurosurgical and Anaesthetic teams, the patient was admitted at 39 weeks and 1 day for induction of labour using of intra-vaginal prostaglandin followed by amniotomy and a syntocinon infusion. The patient only required oral analgesia, pethidine injection and Entonox for pain relief. She had a normal vaginal delivery. Active management of third stage was carried out. She sustained a second degree tear with a minor post-partum haemorrhage (estimated blood loss of $900 \mathrm{ml}$ ). The tear was sutured under local anaesthesia. A live male infant of $3704 \mathrm{~g}$ was born in good condition. Following the delivery, the patient reported fewer episodes headache and there was no change in her neurological status. Four months following the delivery, repeat MRI was arranged and showed good relief of neural compression (Figure 2). 


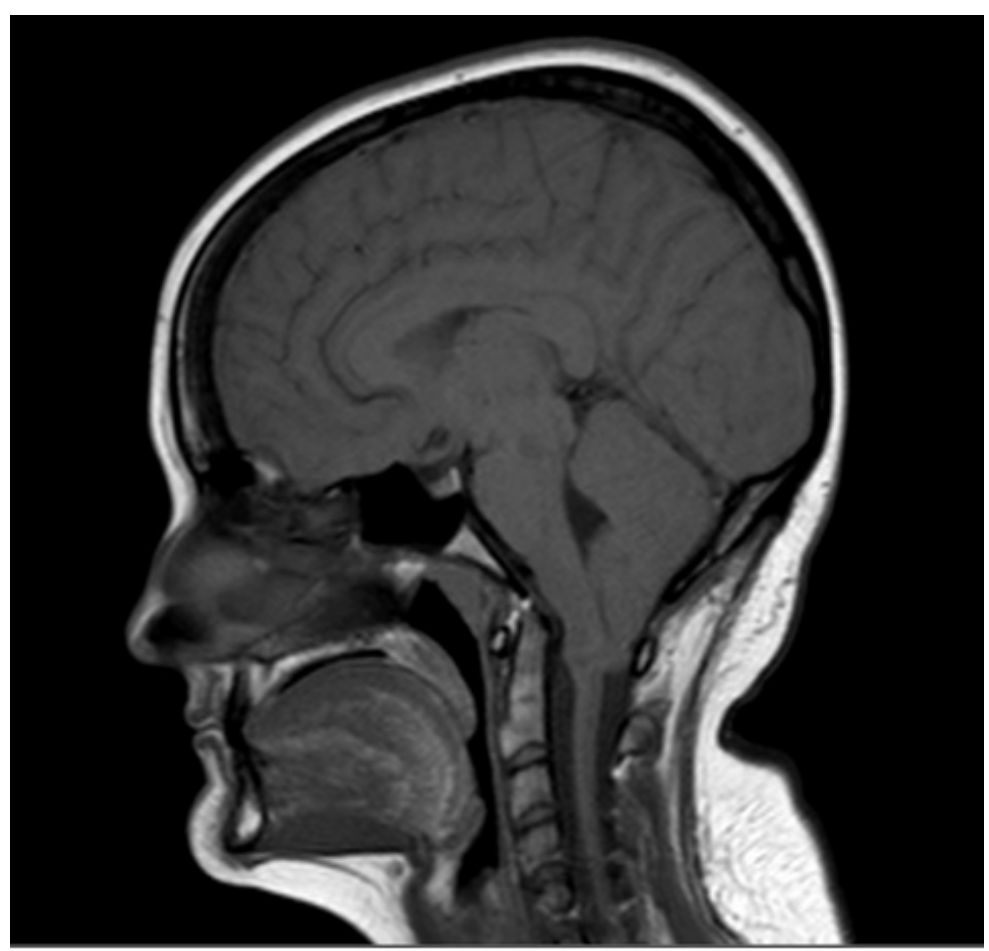

Figure 1. Pre-operative MRI head.

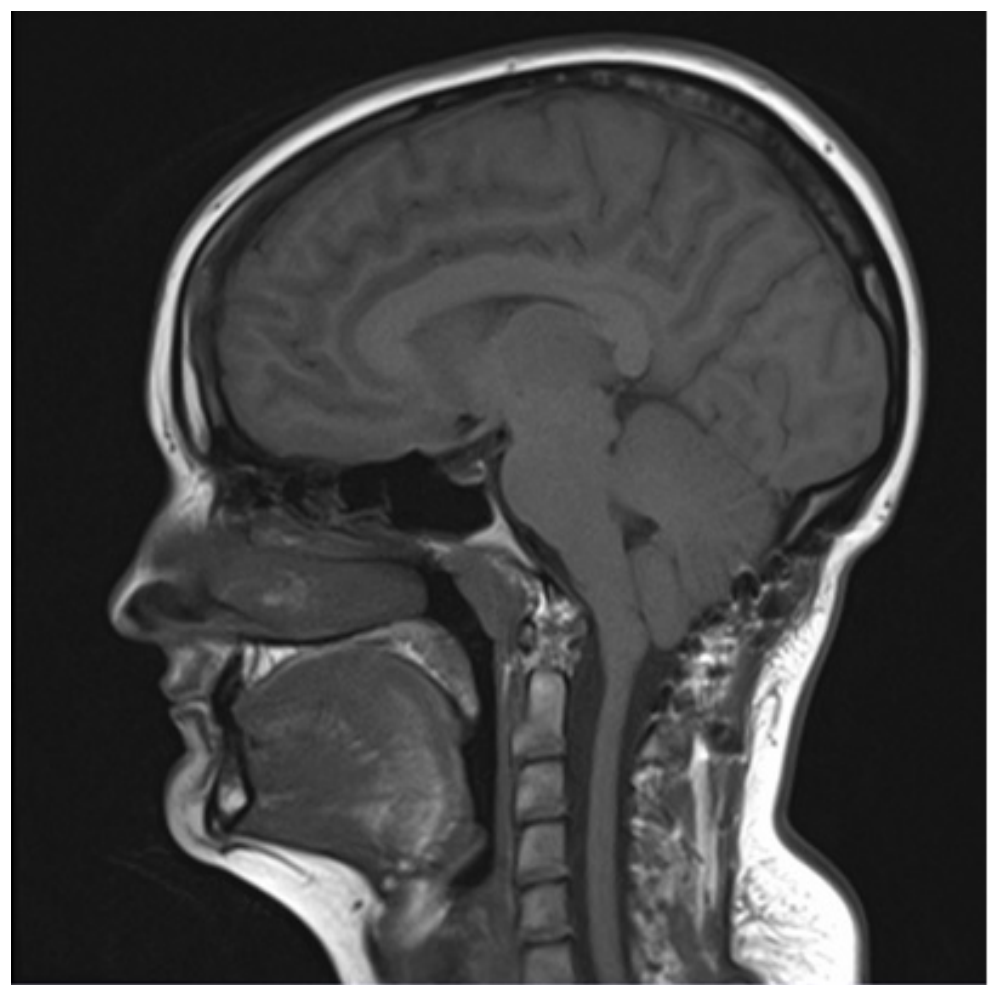

Figure 2. Post-operative MRI head.

\section{Discussion}

Due to limited availability of review and literature on the obstetric and anaesthetic management of patients with 
type I ACM in pregnancy, considerable debates exist concerning the care of these patients [9] [10]. There is no standardised recommendation regarding the mode of delivery (normal vaginal delivery versus operative delivery) and the use of anaesthetic methods (regional as opposed to general) [11].

Most publications revealed that patients with type I ACM (with or without surgical decompression) underwent planned Caesarean section owing to the increase in ICP during labour [12]. The peripartum care of these patients aims to reduce the risk of labour-induced stress and further increase in ICP caused by pushing in second stage [9].

Patients with type I ACM delivered by vaginal operative delivery without maternal voluntary expulsive effort under epidural anesthesia have been reported [13]. No complication was documented during or after the delivery.

Spinal anaesthesia has also been safely used for patients who had surgical decompression of type I ACM [12]. It was believed that spinal anaesthesia could reduce the risk of toxicity caused by local anaesthetics and avoid cerebrospinal fluid (CSF) leakage during accidental puncture of the dura. In 2005, Mueller and Oro presented a case series of 7 patients with type I ACM who had uncomplicated pregnancy, labor and delivery [14]. Four women had vaginal delivery after surgical decompression. The remaining three patients delivered vaginally after diagnosis of ACM but prior to surgical correction. Three of the seven patients had epidural anesthesia for vaginal delivery and no complication was reported. Nevertheless, general anaesthesia would be more appropriate than regional anaesthesia in patients with signs of raised ICP as it can avoid secondary insult from hypotension and hypoxia due to CSF pressure fluctuation and ICP elevation [12].

This patient reported is a multiparous woman with previous successful and uncomplicated normal vaginal deliveries. In spite of the increase in severity of headache in the third trimester, there was no concern regarding raised ICP following surgical decompression on clinical examination. Planned induction and vaginal delivery with close monitoring during labour was thought to be appropriate.

ACM type I is a rare neurological disorder with significant potential morbidity. Successful management of pregnant women presenting with ACM depends on individual assessment of risk factors and multidisciplinary approach [15] [16]. This case report emphasises early recognition of this rare, non-pregnancy related disorder and the importance of a multidisciplinary approach in the care and management of the pregnancy. An individualised delivery plan can be made with the input of the obstetrician, obstetric anaesthetist and neurosurgeon. Early recognition and treatment of type I ACM in pregnant women lead to good outcome and uncomplicated delivery in the majority of the patients.

\section{Acknowledgements}

We thank the patient described for allowing us to share her details.

\section{Patient Consent}

Written consent obtained from patient.

\section{Disclosure of Interests}

All authors report no conflicts of interest.

\section{Contribution to Authorship}

\section{Patricia Ip}

Group 1-Substantial contributions to conception and design, acquisition of data, analysis and interpretation of data

Group 2-Drafting the article and revising it critically for important intellectual content

Group 3-Final approval of the version to be published

\section{Susmita Pankaja}

Group 1-Substantial contributions to conception and design, acquisition of data, analysis and interpretation of data

Group 2-Revising it critically for important intellectual content

Group 3-Final approval of the version to be published

\section{Fidelma O’Mahony}


Group 1-Substantial contributions to conception and design, acquisition of data, analysis and interpretation of data

Group 2-Revising it critically for important intellectual content

Group 3-Final approval of the version to be published

\section{Details of Ethics Approval}

Not applicable.

\section{Funding}

Not applicable.

\section{References}

[1] Williams, B. (1991) Malformations. In: Swash, M. and Oxybury, J., Eds., Clinical Neurology, Churchill Livingstone, Edinburgh, 1533-1582.

[2] Milhorat, T.H., Chou, M.W., Trinidad, E.M., Kula, R.W., Mandell, M., Wolpert, C., et al. (1999) Chiari I Malformation Redefined: Clinical and Radiographic Findings for 364 Symptomatic Patients. Neurosurgery, 44, 1005-1017. http://dx.doi.org/10.1097/00006123-199905000-00042

[3] Meadows, J., Kraut, M., Guarnieri, M., Haroun, R.I. and Carson, B.S. (2000) Asymptomatic Chiari Type I Malformations Identified on Magnetic Resonance Imaging. Journal of Neurosurgery, 92, 920-926. http://dx.doi.org/10.3171/jns.2000.92.6.0920

[4] Speer, M.C., Enterline, D.S., Mehltretter, L., Hammock, P., Joseph, J., Dickerson, M., et al. (2003) Chiari Type I Malformation with or without Syringomyelia: Prevalence and Genetics. Journal of Genetic Counseling, 12, 297-311. http://dx.doi.org/10.1023/A:1023948921381

[5] Ghaly, R.F., Candido, K.D., Sauer, R. and Knezevic, N.N. (2012) Anesthetic Management during Caesarean Section in a Woman with Residual Arnold-Chiari Malformation Type I, Cervical Kyphosis, and Syringomyelia. Surgical Neurology International, 3, 26. http://dx.doi.org/10.4103/2152-7806.92940

[6] Schijman, E. (2004) History, Anatomic Forms, and Pathogenesis of Chari I Malformations. Child's Nervous System, 20, 323-328. http://dx.doi.org/10.1007/s00381-003-0878-y

[7] Aitken, L.A., Lindan, C.E., Sidney, S., Gupta, N., Barkovich, A.J., Sorel, M., et al. (2009) Chiari Type I Malformation in a Paediatric Population. Pediatric Neurology, 40, 449-454. http://dx.doi.org/10.1016/j.pediatrneurol.2009.01.003

[8] Henriques Filho, P.S. and Pratesi, R. (2009) Sleep Disorder: A Possible Cause of Attention Deficit in Children and Adolescents with Chiari Malformation Type II. Arquivos de Neuro-Psiquiatria, 67, 29-34. http://dx.doi.org/10.1590/S0004-282X2009000100008

[9] Landau, R., Giraud, R., Delrue, V. and Kern, C. (2003) Spinal Anesthesia for Cesarean Delivery in a Woman with a Surgically Corrected Type I Arnold Chiari Malformation. Anesthesia \& Analgesia, 97, 253-255. http://dx.doi.org/10.1213/01.ANE.0000066312.32029.8B

[10] Bag, T., Saha, D.P., Dutta, R., De, A.K. and Shah, A. (2012) A Successful Pregnancy Outcome after Antenatal Surgical Decompression of Arnold Chiari Malformation. The Journal of Obstetrics and Gynecology of India, 62, 13-15. http://dx.doi.org/10.1007/s13224-013-0357-7

[11] Krysztof, M.K. (2004) Spinal Anesthesia for Cesarean Delivery in a Parturient with Arnold-Chiari Type I Malformation. Canadian Journal of Anesthesia, 51, 639. http://dx.doi.org/10.1007/BF03018412

[12] Chantigian, R.C., Koehn, M.A., Ramin, K.D. and Warner, M.A. (2002) Chiari I Malformation in Parturients. Journal of Clinical Anesthesia, 14, 201-205. http://dx.doi.org/10.1016/S0952-8180(02)00342-2

[13] Parker, J.D., Broberg, J.C. and Napolitano, P.G. (2002) Maternal Arnold-Chiari Type I Malformation and Syringomyelia: A Labor Management Dilemma. American Journal of Perinatology, 19, 445-450. http://dx.doi.org/10.1055/s-2002-36841

[14] Mueller, D.M. and Oro', J. (2005) Chiari I Malformation with or without Syringomyelia and Pregnancy: Case Studies and Review of the Literature. American Journal of Perinatology, 22, 67-70. http://dx.doi.org/10.1055/s-2005-837271

[15] Newhouse, B.J. and Kuczkowski, K.M. (2007) Uneventful Epidural Labor Analgesia and Vaginal Delivery in a Parturient with Arnold-Chiari Malformation Type I and Sickle Cell Disease. Archives of Gynecology and Obstetrics, 275, 311-313. http://dx.doi.org/10.1007/s00404-006-0215-2

[16] Sicuranza, G.B., Steinberg, P. and Figueroa, R. (2003) Arnold-Chiari Malformation in a Pregnant Woman. Obstetrics \& Gynecology, 102, 1191-1194. http://dx.doi.org/10.1016/S0029-7844(03)00682-3 
Scientific Research Publishing (SCIRP) is one of the largest Open Access journal publishers. It is currently publishing more than 200 open access, online, peer-reviewed journals covering a wide range of academic disciplines. SCIRP serves the worldwide academic communities and contributes to the progress and application of science with its publication.

Other selected journals from SCIRP are listed as below. Submit your manuscript to us via either submit@scirp.org or Online Submission Portal.
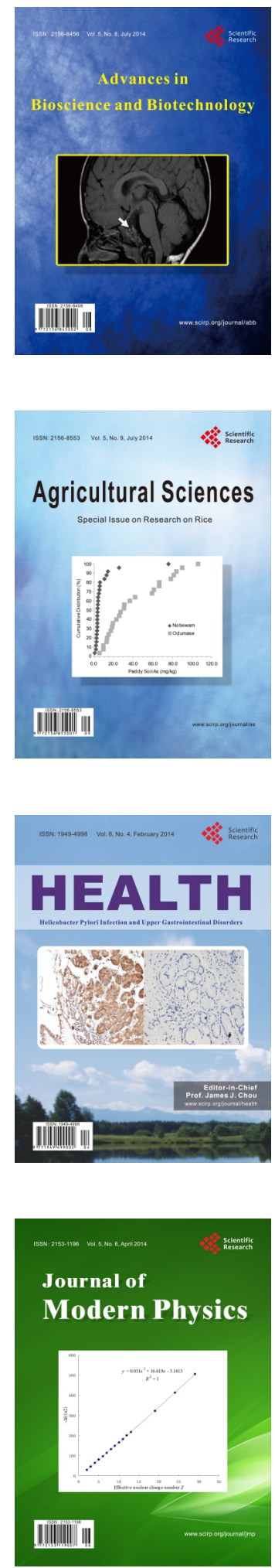
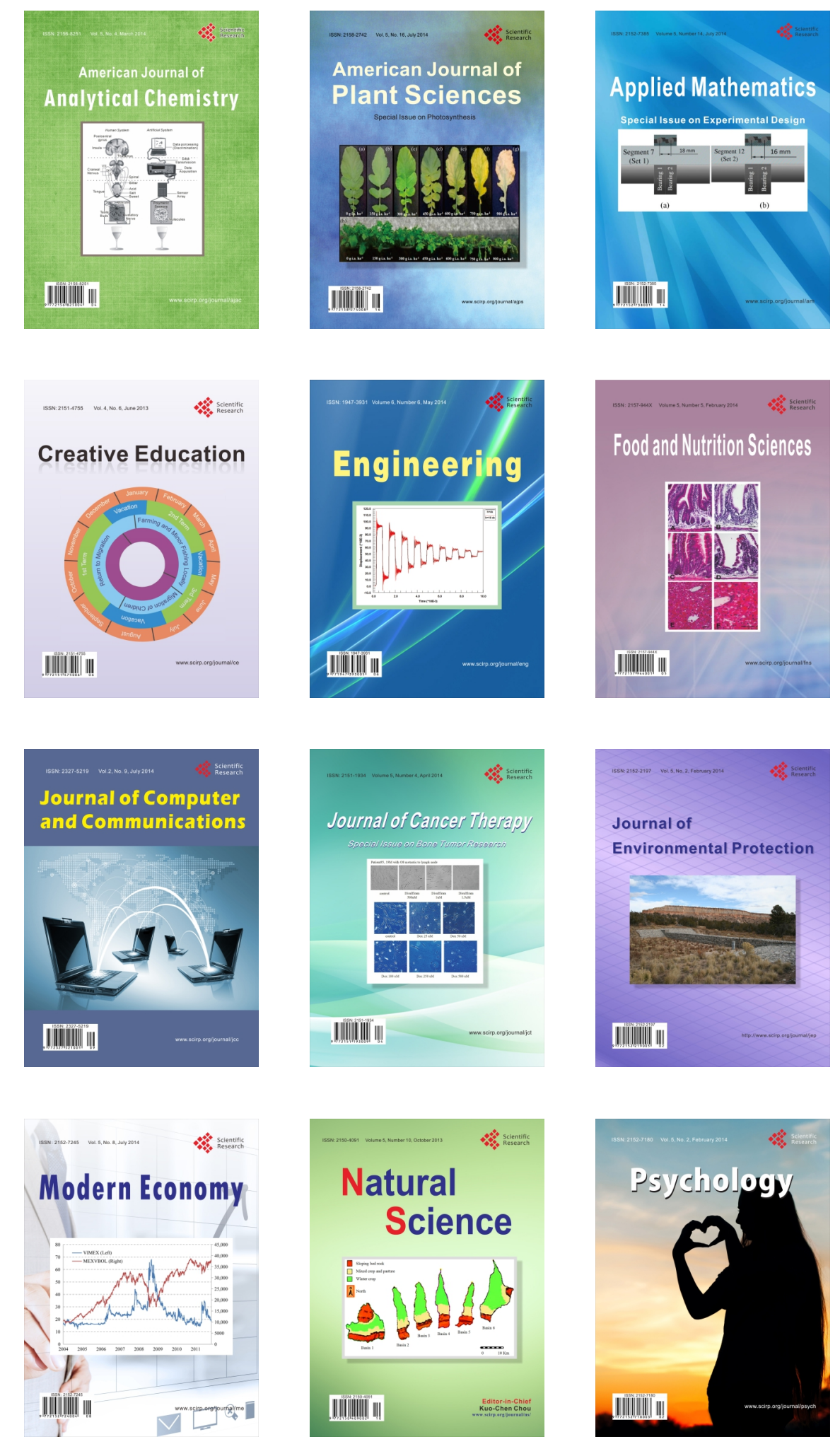